\title{
Arabesco e Grotesco na arquitetura de Peter Eisenman
}

\section{Elizabeth Garcia}

Mestre em Arquitetura pela PUC-Rio, 2019

Contato: elizabgarcia@gmail.com

\section{Otavio Leonídio}

Arquiteto. Doutor em História. Professor associado do Departamento de Arquitetura e Urbanismo da PUC-Rio.

Contato: o.leonidio@uol.com.br

\section{RESUMO}

Esse artigo pretende destacar a eficácia dos conceitos de Arabesco e Grotesco na arquitetura "entre" de Peter Eisenman, evocando todo um sistema de conceitos e metodologias que conduziram sincronicamente o seu trabalho.

Palavras-chave: Peter Eisenman; arquitetura; teoria; modernismo; arabesco; grotesco; significado; representação.

\section{ABSTRACT}

This paper intends to highlight the effectiveness of the concepts of Arabesque and Grotesque in the architecture "between" of Peter Eisenman, evoking a whole system of concepts and methodologies that synchronously led his work.

Keywords: Peter Eisenman; architecture; theory; modernism; arabesque; grotesque; meaning; representation.

Este texto é um desdobramento da dissertação de mestrado de Elizabeth Garcia, defendida em 28/02/19, no Programa de Pós Graduação em Arquitetura da PUC-Rio, com orientação de Otávio Leonidio.

Todas as imagens foram retiradas do site Eisenman Architects. 
Peter Eisenman intempestivamente advertiu: o movimento moderno não teve lugar na arquitetura. Tudo que a arquitetura moderna realizou foram mudanças estéticas. A relação entre forma e função, uma característica da arquitetura desde o Renascimento, permaneceu intacta. O que significa dizer que, desde o século XV, a arquitetura esteve presa ao paradigma clássico — ou, nos termos de Eisenman, ao compromisso com o intemporal, o significativo e o verdadeiro.

Para que a arquitetura participe do pensamento contemporâneo, adverte ele, é preciso que renuncie às oposiçôes dialéticas entre estrutura e ornamento, abstração e representaçáo, figura e fundo, forma e função. Para tanto, deve explorar o "entre", e deixar para trás a necessidade de representar: função, abrigo e estabilidade. A elaboração de uma arquitetura "entre" move-se, portanto, de uma preocupação com o objeto como essência ideal (ou seja, um objeto que se pretende verdadeiro em sua representação metafórica) para o objeto como texto de deslocamento, o que inclui a ficção e o erro.

O que para Eisenman é o "entre" em arquitetura? Em suas palavras, "estar entre significa estar entre algum lugar e nenhum lugar, significa buscar um atopos, a atopia dentro do topos ${ }^{1}$. Para tanto, Eisenman recorreu a dois termos: o arabesco e o grotesco. Em Blue Line Text ele apresenta o arabesco e o grotesco para descrever a sua disposição a (re)pensar os limites da arquitetura. Partindo do desejo de deslocar o pressuposto central da dialética metafísica (na qual surgiram pares de oposiçôes como forma e função, estrutura e ornamento e figura e abstração), Eisenman destaca o arabesco como um exemplo sugestivo do "entre". Em suas palavras:
"O Arabesco está entre a figuração e a abstração, entre a natureza e o homem, entre significado e forma. Tradicionalmente seu uso tem sido meramente decorativo, mas é possível sugerir a presença da estrutura no arabesco ou, pelo menos, delimitar a condição entre estrutura e ornamentação" ${ }^{2}$.

Eisenman destaca ainda os vínculos existentes entre esses pares de oposição dialéticos e um sistema totalitário de valores - por exemplo, estrutura é bom, ornamento é ruim. Desse modo, o arabesco age como um fator que não busca propriamente a separação de categorias, mas turvar os sistemas classificatórios tradicionais. Os pares dialéticos, tomados por regra como resolvidos, passam a ser problematizados pela exploração do "entre". Desfaz-se, assim, a convenção que impóe um significado único aos elementos arquitetônicos.

Contudo, muito mais do que negar um significado, Eisenman se dispóe a elaborar as possibilidades de significados "outros". É assim que deve ser entendido o arabesco: algo que define um "entre" — e não um elemento (figurativo ou abstrato) que pode ser identificado em cada uma de suas obras. Essa ideia de falta de clareza pela turvação da realidade não é, contudo, menos racional; trata-se de admitir o irracional no racional. E o mesmo se dá com o grotesco:

"Analogicamente, o grotesco, cujas raízes são relacionadas às do arabesco, pode ser usado para explorar o 'entre'. Não é coincidência que se façam alusôes aos trabalhos de Sherman e Salle como grotescos. Nos Contos do Arabesco e do Grotesco, de Edgar Allan Poe, a casa 
mal-assombrada é uma imagem central. Isso não quer dizer que devamos literalmente construir casas mal-assombradas, nem romancear a qualidade do assombrado, mas sim que o grotesco talvez esboce um potencial poético, uma possibilidade para a arquitetura do 'entre', hoje"3.

O potencial poético representado pela figura do grotesco é o que permite a reinvençáo da linguagem, aquilo que leva as coisas à sua plenitude. A linguagem poética é o terreno fértil onde um signo nunca será unívoco. Essa liberdade do dizer poético cria o espaço para o desenvolvimento da experimentação. $\mathrm{O}$ resultado não pode ser determinado pelos sistemas de poder, convençóes gramaticais ou regras rígidas. $\mathrm{O}$ que é regra nunca é poético. E não nem é tampouco invenção.

Nas pinturas de David Salle e as fotografias de Cindy Sherman, Eisenman identifica o nebuloso que existe entre o belo e o feio. Mais: também o belo no feio e o feio no belo. $\mathrm{O}$ grotesco atua como alegoria tanto para o poético como para a condiçáo de interstício. Na poética clássica, o grotesco se caracteriza pelo indeterminado, indizível e geralmente pensado como o negativo do sublime. $\mathrm{O}$ sublime diz respeito às qualidades do etéreo. $\mathrm{O}$ grotesco tem a ver com a substância concreta, com a manifestação do incerto no mundo físico. Enquanto o conceito de belo reprime, pela categorização de feio, tudo que não é belo, o sublime ${ }^{4}$, por tratar da condição do que é incerto, indizível, não natural e náo físico, contém em si o grotesco, e não se opóe a ele. Existe aqui uma diferença importante entre "se opor a" e "estar contido em". A arquitetura do "entre" não se refere a um entre dialético, mas um entre "dentro de" (“between within") 5 .
Eisenman observa que, no passado, a metáfora foi usada na arquitetura para expressar forças como tensão, compressão, extensão e alongamento. Entretanto, a ideia de metáfora apresentada aqui não serve para expressar esses efeitos (gerados entre edifícios ou entre espaços e edifícios), mas sim para representar a ideia de que o próprio processo interno pode dar origem a uma figuração não representacional no objeto. Nesse sentido, não se trata de uma exploração da estética clássica do objeto, e sim da poética potencial de um texto arquitetônico.

O poético posto em prática por Eisenman é a ação de tornar manifesto o indizível - a poesia definida como linguagem que comunica de modo profundo e contundente, uma ou qualquer realidade, abrindo espaço para o entendimento de outras realidades possíveis. A invenção passa a abarcar a realidade que não está presa a procedimentos racionais, nem ao mero funcionamento ou representação da arquitetura.

Eisenman é categórico ao considerar a arquitetura como uma linguagem. E, como Heidegger ${ }^{6}$, Nietzsche e Merleau-Ponty, acredita que a poesia é a essência da linguagem. $\mathrm{O}$ projetar poeticamente de Eisenman não se refere literalmente à poesia, mas ao pensar com uma sensibilidade poética, caracterizada pela impossibilidade de definir fronteiras limitadas para o lugar, a realidade e a verdade. Uma ação que nega o formalismo e postula a liberdade face aos paradigmas da disciplina.

$*$

Em "Tlön, Uqbar, Orbis Tertius" (conto do livro Ficções, de J. L. Borges) o narrador encontra por acaso uma enciclopédia com uma descrição sumária da história total de um planeta desconhecido chamado Tlön, criado por uma organização secreta de inte- 
lectuais: Orbis Tertius. Conjectura-se que esse novo mundo é obra de uma sociedade secreta de astrônomos, biólogos, engenheiros, metafísicos, poetas, químicos, pintores, filósofos, geômetras, etc, todos eles dirigidos por um obscuro homem de gênio 7 . Mas o ponto relevante aqui é a linguagem: na língua de Tlön, não existem substantivos, apenas verbos ou advérbios. Por exemplo, como não existe um termo que corresponda à palavra lua, emprega-se um verbo que pode ser lunecer ou lunar. Assim para comunicar que surgiu a lua sobre o rio, diz-se: para cima atrás duradouro-fluir luneceu. A questáo não se conclui, contudo, pois essa regra concerne meramente à gramática do hemisfério austral. No hemisfério boreal, por outro lado, a célula primordial não é o verbo, mas o adjetivo. Como decorrência, o substantivo se forma por uma acumulação de adjetivos. Desse modo, não se diz lua, diz-se aéreo-claro sobre escuro-redondo, e assim os objetos ideais são formados e dissolvidos com quantos acréscimos forem necessários às necessidades poéticas. Por isso em Tlön há poemas famosos compostos apenas de uma única enorme palavra. Ao descrever as linguagens de Tlön, Borges suscita a questấo de como a linguagem influencia as possibilidades do pensamento e a criação da realidade. A lição vale para Eisenman, que critica o sentido de verdade usando a poética do "entre" para explorar o deslocamento entre lugares e não lugares, o topos e o atopos; descobrindo os não lugares para reinventar o lugar. Do mesmo, pretende penetrar na metáfora para revelar a catacrese, penetrar no atopos para revelar um novo topos.

O Arabesco e o Grotesco referem-se à figura retórica catacrese, uma figura não-representacional, que se distinguem da figura metafórica exatamente por representar uma coisa na ausência dela. A figura retóri-
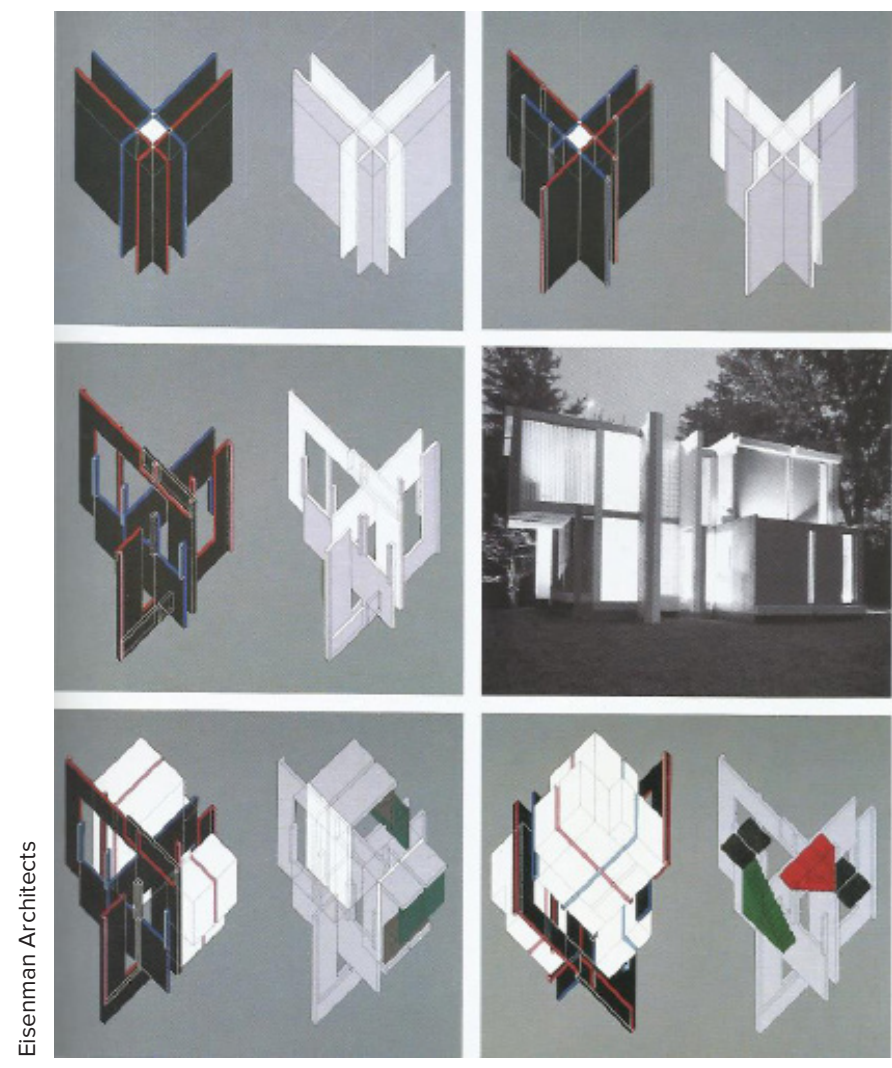

Casa VI — Diagramas axonométricos — Fachada

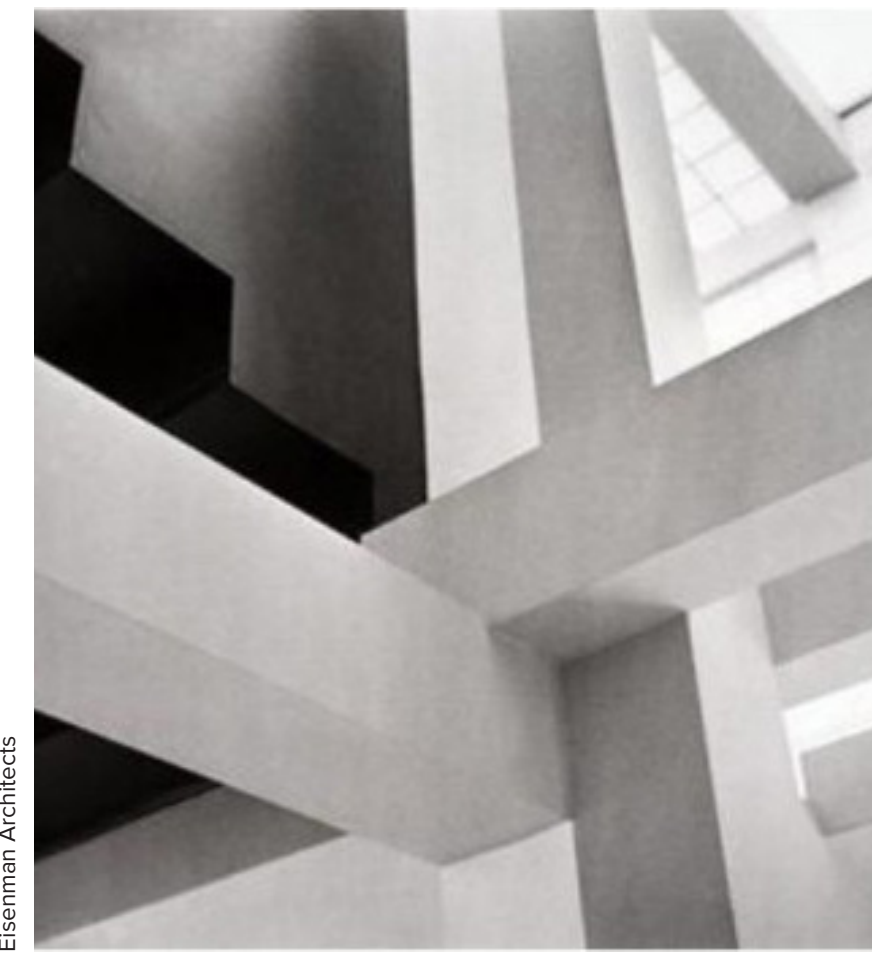

Casa VI - Detalhes do interior 


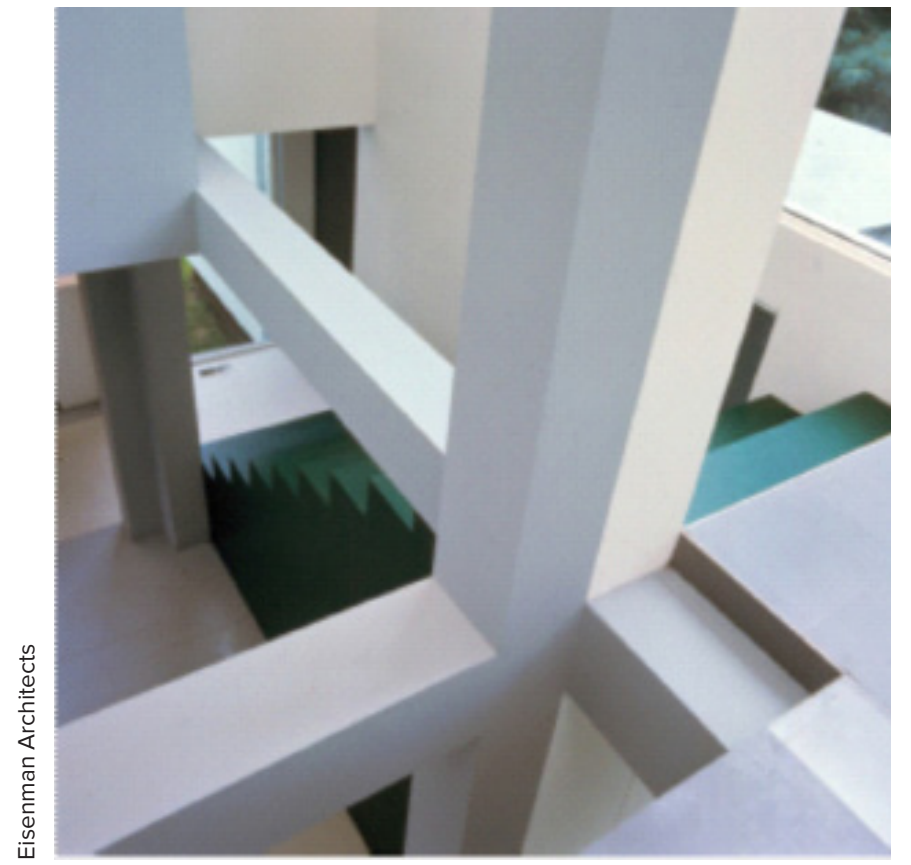

Casa VI - Detalhes do interior

ca proposta por Eisenman contém a sua ausência, ou seja, contém a indeterminação de seu sentido. Uma vez que o índice em relação ao relatado é desprovido de uma representação psíquica, o discurso de tipo metafórico, no qual prevalece o domínio das associações substitutivas, torna-se infactível.

Empenhado em produzir um "texto" arquitetônico Eisenman criou mecanismos projetuais estratégicos, sendo o principal, o traço. Esse sistema de signos permite ao objeto tornar-se legível por meio de um signo - mais especificamente, o índice, ou seja uma espécie de presença da ausência. Um sistema de diferenças (ou um registro visual de um sistema) que permite o registro do movimento que nos induz a ler o objeto na relação com outros movimentos prévios ou subsequentes.

A Casa VI, construída em 1975 no estado de Connecticut, em Cornwall é um excelente exemplo de como Eisenman subordinou sua invenção a um plano sistemático. Seu compromisso: produzir signos e formas que não remetem um ao outro, mas sim à forma final, que mantém sempre os rastros do processo, índices que lhes servem de evidências.

Temos aqui uma série de exemplos de arabescos, ou seja, amostras de turvamentos dos elementos classificatórios tradicionais. Não sendo nem ornamento nem estrutura, esses elementos são, de fato, um indicativo da especificidade da arquitetura, na medida em que registram o processo pelo qual a arquitetura teve origem. São os traços que constituem sua proposta de "texto". Eisenman ressalta que o que está sendo lido náo é o objeto em si, mas o ato de dar forma. O traço é o registro do movimento que nos induz a ler o objeto "presente" como um sistema de relaçôes com outros movimentos precedentes ou subsequentes, desprovido de significados prévios. A arbitrariedade empregada nessas operaçôes é usada para estimular, ou induzir, a leitura dos traços sem referências ao significado, mas às condiçóes do processo. O processo mostra o "como", promove a pura leitura, sem valor ou preconceito. Ou seja, o que ocorre é o oposto da interpretação: o "texto" não permite nunca um único significado. Tudo é mostrado para significar mais de uma coisa.

A Casa VI é, simultaneamente, objeto e uma espécie de manifestação cinematrográfica do processo de transformação. Assim, o objeto não é apenas o resultado final de sua própria história, contém também esta história, servindo de registro completo - processo e produto, que assim se tornam intercambiáveis.

A utilização de um elemento funcional específico é empregada aqui de modo totalmente deslocado. A posiçáo das escadas é, pela geometria euclidiana, assimétrica, mas é simétrica pela geometria topológica, 


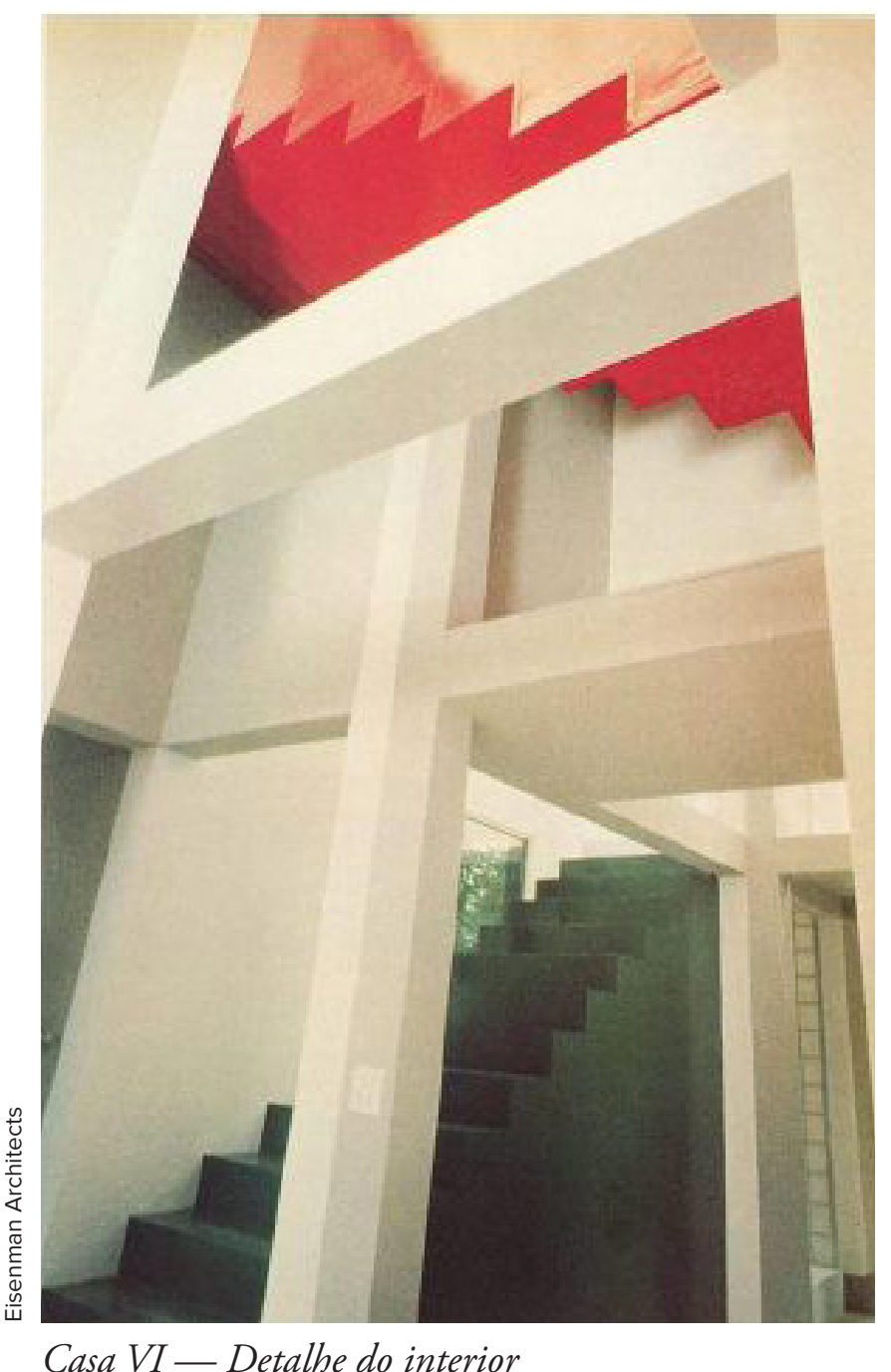

Casa VI - Detalhe do interior

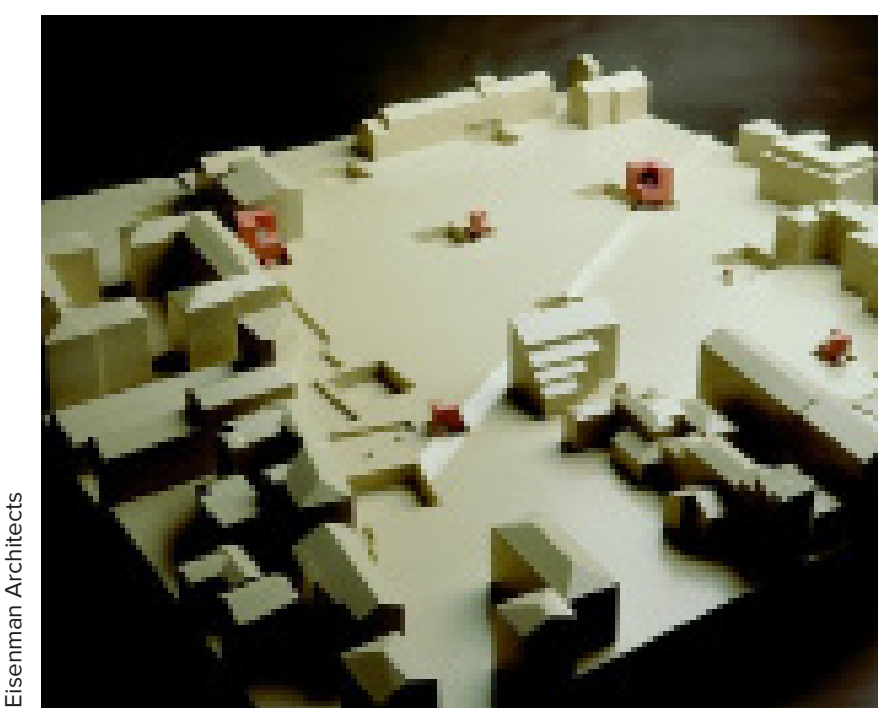

Cannaregio - Maquete o que causa desorientação sobre o que é o lado de cima e o que é o lado de baixo. Perde-se assim qualquer possibilidade de relacionamento com o terreno ${ }^{8}$ e no limite a própria ideia de "lugar" entra em colapso.

Essa duplicação e essa inversão promovem uma nova relação do signo e de seu uso. A poética do grotesco, expressa no emprego de um lugar comum fora de seu lugar, propicia o estranhamento. Em The architectural Uncany (1992), Anthony Vidler desenvolveu um estudo sobre o lado obscuro do sublime, o uncany, ou o “estranhamente familiar” - uma categoria estética e freudiana que coloca em primeiro plano o corpo e o sujeito em relação à experiência vivida da arquitetura. Em suas palavras:

"Em sua dimensão estética, o estranhamente familiar é uma representação de um estado mental de projeção que justamente elimina as fronteiras do real e do irreal afim de provocar uma ambiguidade perturbadora, um deslizamento entre a vigília e o sonho"?.

Apresentando um "texto grotesco", feito de estranhamento e ambiguidade, e o "texto arabesco" que turva a dialética figura/fundo, Eisenman promove uma reestruturação do sujeito através da reinvenção da percepção do objeto em relação ao espaço e em relaçáo ao uso desse espaço. A Casa VI é uma profusão de arabescos da ausência e de grotescos da presença.

No projeto de Cannaregio (1978) Eisenman empregou arabescos da memória e grotescos da escala, construindo uma Veneza fictícia que se sobrepóe à malha urbana existente. Seu projeto se sobrepóe também à malha do projeto proposto por Le Corbusier em 1964 para a mesma área. A malha de Eisenman 
é também o traço de uma ausência - constituído por uma série de vazios que são "uma metáfora para o deslocamento do homem da sua posição como instrumento central de medida" 10 .

O novo topos não é mais um lugar específico, dotado de escala e tempo específico, senão um desfoque contínuo de lugar, escala e tempo ${ }^{11}$. Desse modo, o "texto" projetado por Eisenman desloca os aspectos de presença, origem, lugar, escala, etc.

A operação conta, para tanto, com versóes em diferentes escalas da Casa XIa, que foram colocadas nos intervalos em que o traçado coincidia com os espaços abertos existentes no terreno. A operação subverteu qualquer ideia estabelecida de escala. $\mathrm{O}$ objeto menor, quando posicionado no espaço urbano de Cannaregio, é muito pequeno para ser uma casa, o que levanta a questão de que talvez seja a maquete de uma casa. Quando colocado em escala 1:1, contudo, a casa não mantém sua função de casa, torna-se um tipo de mausoléu. Assim como o objeto maior retém o menor, este deixa de ser uma maquete e se transforma em objeto em si. Por último, um terceiro objeto é colocado no mesmo contexto, desta vez maior que os outros dois e maior que em escala antropomórfica. Completa-se assim o ciclo auto-reflexivo. Uma vez que, o maior contém o médio e o menor, torna-se o museu de um memorial ${ }^{12}$. Reunidos, os objetos escapam aos limites da arquitetura, e colocam em questão a ideia de significado como efeito da função.

$\mathrm{O}$ que Eisenman faz em Cannaregio é, sobretudo, uma "poética textual" que expôe as camadas do tempo e o sentido da memória, rompendo as fronteiras de presente, passado e futuro. "Todas as três memórias, futuro, presente e passado têm a sua sombra, a perda da memória. Talvez devêssemos agora apren-

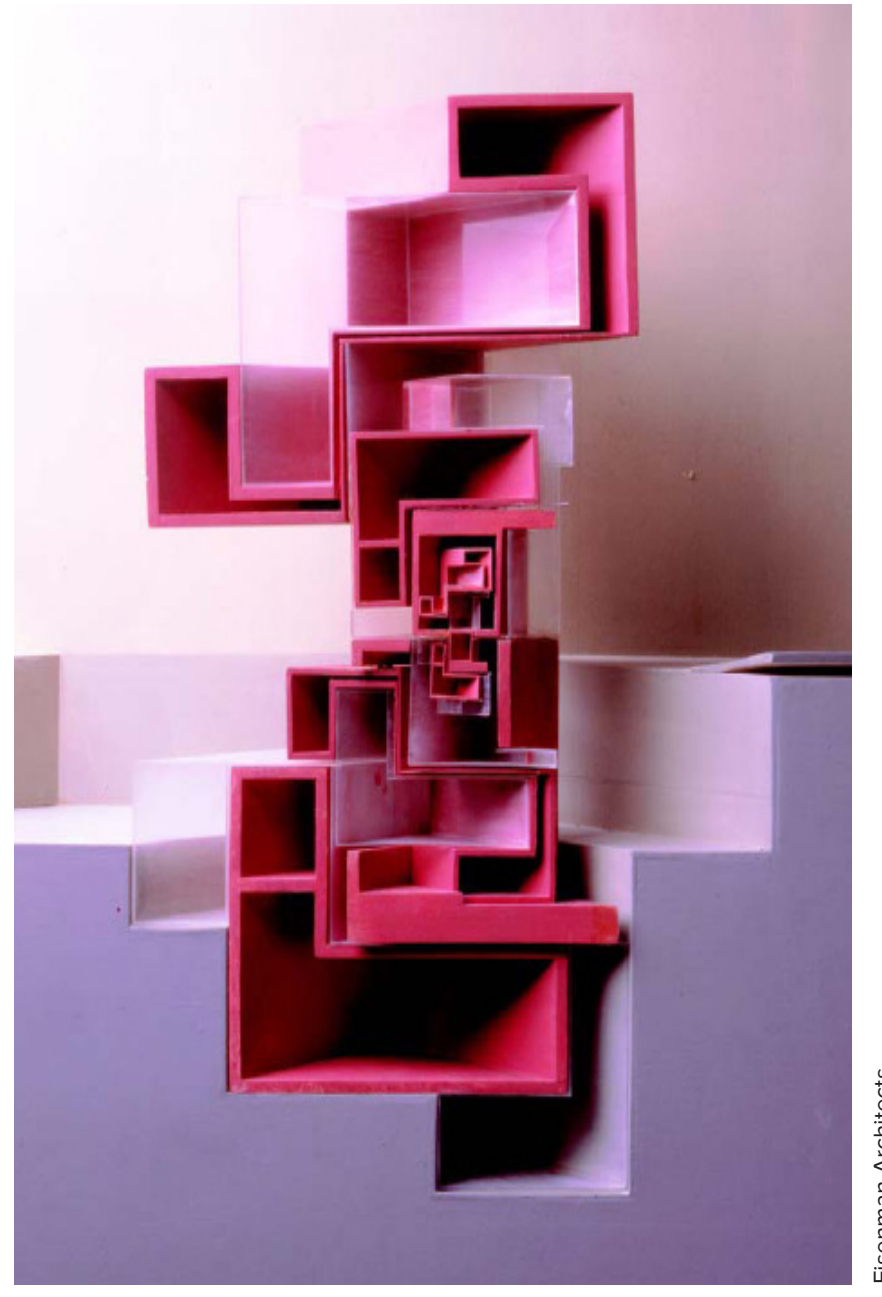

Casa Inabitável Cannaregio - Maquete três versóes da casa XIa

der como esquecer"13.

Uma concepção "outra" do espaço, com uma distinção entre traço e marca, introduziu-se no trabalho de Eisenman com o projeto da Casa Guardiola, de 1988, dando continuidade a sua pesquisa do "entre" na arquitetura. Essa definição "outra" de espaço já fora sugerida na antiguidade no Timaeus de Platão, em sua definição de receptáculo (chora), como algo que existe entre lugar e objeto, entre recipiente e conteúdo. Eisenman lança mão da noçáo chora empregada por Jacques Derrida ${ }^{14}$, ou seja, a de um es- 


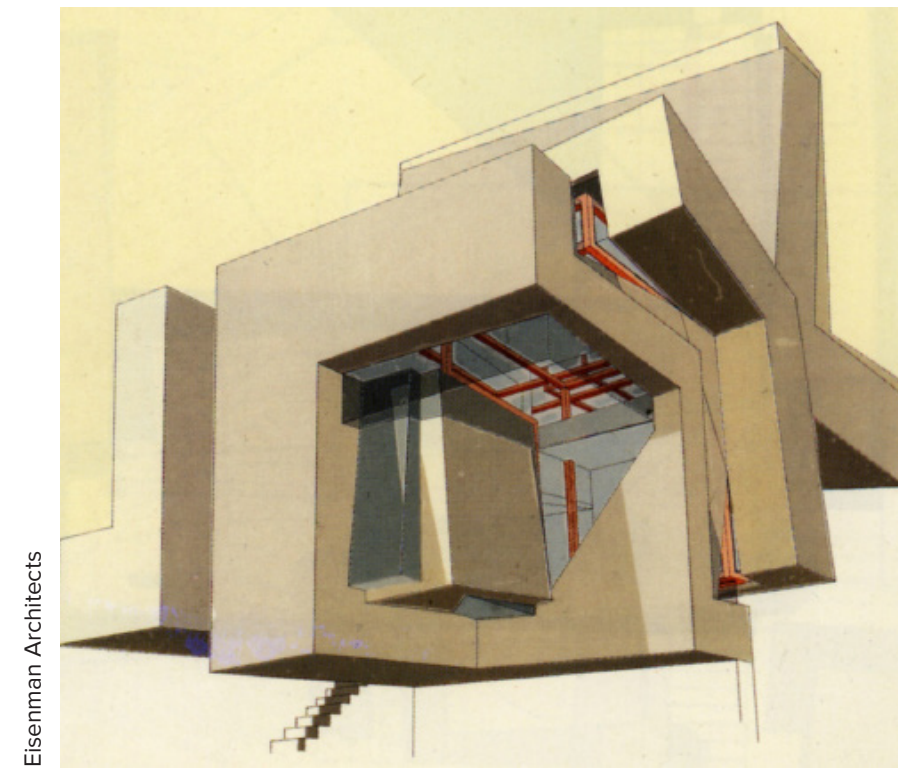

Casa Guardiola - Perspectiva

paçamento, e não de um intervalo. Com esse deslocamento da tradicional forma de lugar, também entram em colapso as categorias tradicionais de figura/ fundo e plano/objeto ${ }^{15}$. O que temos são Arabescos.

Nos primeiros projetos, Eisenman assinala que, antes da ideia de receptáculo, todas as marcas eram, essencialmente, traços, isto é, vestígio de algo que esteve outrora presente. No sentido empregado aqui, o que antes era considerado traço pode agora ser chamado de marca. O receptáculo, conceitualmente é uma construção que tem o potencial de mudar constantemente sua forma, assim como mudar a forma de outro objeto, sem ser material em si. Desse modo, quando algo é pressionado no receptáculo, uma impressão ou marca (e náo um traço) é transmitida, enquanto, simultaneamente, um vestígio (i.e., traço) do receptáculo é deixado no objeto de impressão.

Formas semelhantes ao "L" interpenetram-se, entrelaçando-se em três planos diferentes assentados um no outro. Durante o processo, ocorre uma oscilaçáo ou reverberação entre eles, causando uma reação simultânea. Como decorrência, um provoca uma impressão no outro. Ao mesmo tempo, perde-se algo de sua presença figural original. $\mathrm{O}$ contorno desta presença ausente é então gravado sob uma série de traços, uma estrutura de fotogramas que conservam o testemunho do volume anterior. Essas anotaçóes reproduzem-se no material da casa. Nos pisos, paredes, lajes, até mesmo no próprio espaço ${ }^{16}$. Um tecido de traços referindo-se interminavelmente a algo diferente de si: o texto "entre".

A oscilação inicial é arbitrária, assim como os volumes em L. Do mesmo modo, cada traço sucessivo torna-se um novo, inicialmente ainda arbitrário, mas sendo de algum modo condição necessária, respondendo e antecipando uma sequência contínua de novas condiçôes arbitrárias.

Desse modo, ao contrário de uma noção tradicional de espaço, que tem origem em algum lugar e que, assim, é linear e racional, essa sequência arbitrária, motivada por uma condição inicial, produz uma densa série de marcaçóes no espaço, organizada como uma narrativa da transformação de uma condição inicial.

Aqui, paredes, pisos e tetos não apenas contém e abrigam; tornam-se, também, condição de excesso, na medida em que não contém e nem são contidos, não há dentro nem fora; nem contorno, nem objeto; nem figura, nem fundo. A casa não pode ser lida iconicamente porque, saturada de traços e impressóes, perde o valor icônico, uma vez que não tem referência formal, e tampouco é resultado da funçãa ${ }^{17}$. Uma vez mais, arabescos.

Para Otília Arantes, os procedimentos de deslocamentos empregados aqui, como torções, rotaçôes, vestígios e marcas dos moldes, foram deixados para 
criar uma sensação de incerteza. São nesse sentido grotescos.

A Casa Guardiola é mais um exemplo do "texto de deslocamento" eisenmaniano; náo é lugar específico, tempo específico; não simboliza uso, abrigo ou estrutura, uma vez que o texto não é a fonte originária de imagem ou figuração, nem tampouco representação do uso ou da estética. $\mathrm{O}$ tipo casa foi subvertido. $\mathrm{O}$ arabesco turvou os valores e os sistemas classificatórios tradicionais. $\mathrm{O}$ grotesco possibilitou as fronteiras flutuantes entre o racional e o irracional, entre a lógica e o caos. Sua verdade está em constante fluxo. Arabescos do irracional e grotescos da lógica efetivados.

Em 2004 Eisenman elaborou um projeto repleto de arabescos do tempo e grotescos do espaço nomeado poeticamente de Il Giardino dei Passi Perduti, no Museu de Castelvecchio - um dos mais importantes da cidade de Verona. Em 1957 o arquiteto italiano Carlo Scarpa fora chamado para atuar na obra de restauro, propondo uma intervenção marcadamente destacada da arquitetura original. Para conseguir um diálogo com a obra de Scarpa, Eisenman procurou demonstrar que a luta por caminhos aparentemente díspares também representa uma busca por uma lógica interna para a disciplina da arquitetura. Esta elucubração seria uma amálgama de projetos, e suas reflexôes críticas, um excessivo "hipertexto" que combina texto e objetos além dos limites de sua textualidade anterior.

A exibição em si é um projeto situado, no jardim, como um trabalho didático, e nas galerias, como um trabalho fragmentário. Scarpa utilizou um piso de concreto estriado no interior das cinco salas de exibição. Estes cinco quadrados foram deslocados para o jardim como cinco placas "escavadas", localizadas em um eixo paralelo à sequência interna das salas. Posteriormente, Eisenman transferiu o eixo através do jardim, cruzando diagonalmente e atravessando as placas de Scarpa; destacou ainda a sala contornada no final da sequência de espaços desenhados por Scarpa, sugerindo a preexistência do eixo oblíquo. As placas de concreto são reveladas à medida que se caminha do canto da ponte de Scarpa em direção à entrada do museu. As placas abrem-se em fendas, revelando uma amálgama dos projetos de Eisenman - Cannaregio, IBA Social Housing, Wenex Center for Arts, Musée Du Quai Branly e a Cidade de Cultura da Galícia, em Santiago de Compostela - que irrompem do solo com uma qualidade proustiana de "tempo achado"18.

No interior, a natureza fragmentária das peças que integram os projetos confronta Scarpa e suas temáticas. Esses fragmentos "escavados" do grid de Berlim e do grid cartesiano de Santiago de Compostela, pintados de vermelho, afloram e surgem como uma série de resíduos poéticos nos interstícios entre o piso de Scarpa e as paredes do castelo. Aqui, como no jardim, o tempo torna-se parte de uma rede de caminhos cruzados para um lugar que é passado e futuro $^{19}$. Este projeto demonstra que apesar do tempo transcorrido entre a proposta inaugural de "texto" e sua execução, Eisenman potencializou as possibilidades de exploração do arabesco e do grotesco, mantendo ao mesmo tempo o paradoxo e a busca por uma lógica interna para a disciplina da arquitetura.

Eisenman ao longo de seu trabalho nomeou a sua pesquisa sobre o traço de vários modos diferentes: absoluto formal, estrutura profunda, arquitetura conceitual, deslocamento, texto, presentness ou for- 
mal universal entre outros. O traço é um texto que desloca a escala, o tempo, o lugar, o significado e a função. $\mathrm{O}$ traço é scaling. $\mathrm{O}$ traço é presentness que desloca a presença, introduz a ausência e subverte o tipo. O traço é diagrama que transforma a forma e que é transformada pelo diagrama. $\mathrm{O}$ traço atua entre a interioridade da arquitetura e o processo. O traço é rastro, marca; é tudo que "escreve" o texto. É, enfim, todo o conjunto que trabalha para configurar o arabesco e o grotesco. Portanto, o arabesco e o grotesco concentram uma combinação de artifícios distintos entre a interioridade e o processo, entre a fantasia e o acontecimento, entre a presença e a ausência, entre o racional e o metafísico, entre o diagrama e o objeto.

Se o arabesco é turvamento dos elementos classificatórios tradicionais, não sendo nem ornamento, nem estrutura, mas traço que registra o processo pelo qual a arquitetura teve origem, entáo é o elemento indicativo da especificidade, ou singularidade, da arquitetura. Se o grotesco é a manisfestação do incerto no mundo físico, e o traço é a manifestação da ausênçia na presença, o traço é tanto arabesco quanto grotesco.

\section{*}

Tanto o arabesco quanto o grotesco constituem o "entre" que a pesquisa de Eisenman persegue. Em duas palavras ele evoca todo um sistema de conceitos e uma metodologia que permearão seu processo de trabalho e seu pensamento, criando um repertório de mecanismos gráfico-formais: o arabesco, para o turvamento das hierarquias de valores e sistemas classificatórios tradicionais, e o grotesco como dispositivo poético e de turvamento de categorias: racional, irracional, imaginação e realidade. Dessa forma,

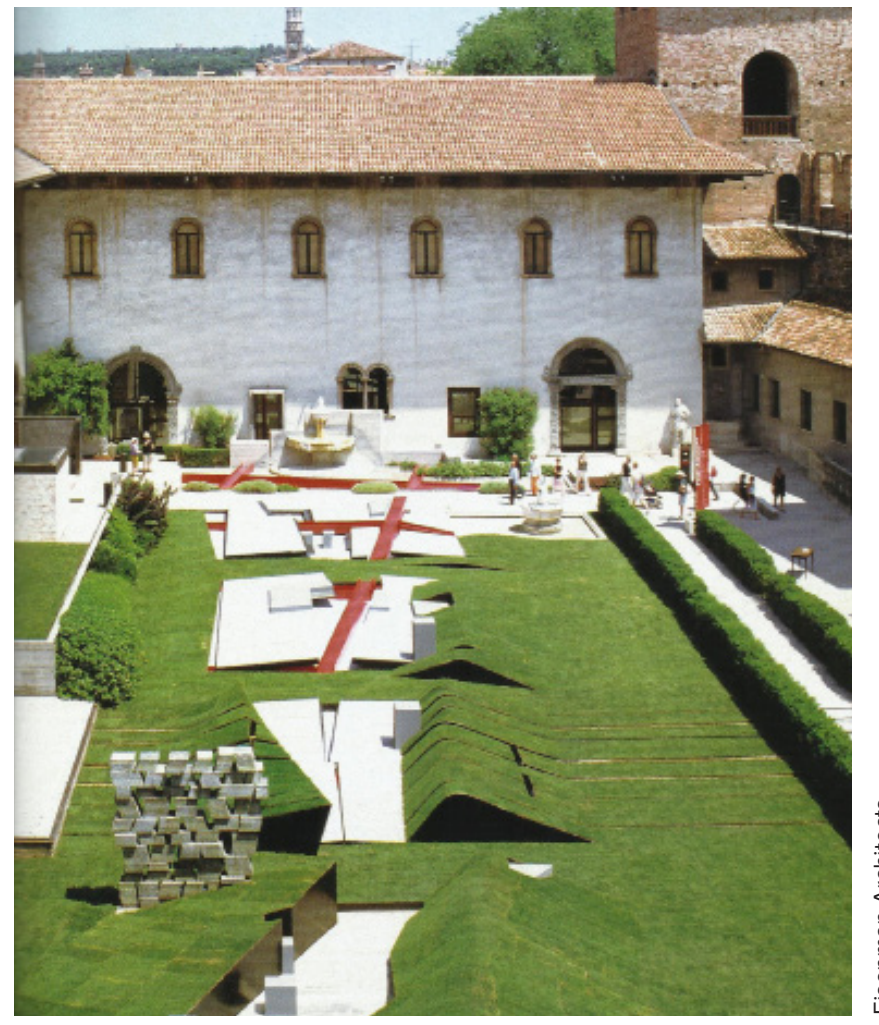

Il Giardino dei Passi Perduti, no Museu de Castelvecchio, 2004

o arabesco e o grotesco deixam de ser meras alegorias e se transformam em textos de deslocamento da arquitetura, convertendo-se assim em dispositivos determinantes do "entre".

De cerâmicas e tapetes à arquitetura, o arabesco foi empregado sempre que os seres humanos pretenderam ornamentar seus objetos. Esse ornamento se deslocou no tempo e no espaço, atravessou a antiguidade, percorreu o mundo clássico, floresceu no arabesco islâmico, singrou o movimento Arts and Crafts, subsistiu no século XX com o Art Nouveau. Até o dia em que, em algum momento do século $\mathrm{XX}$, virou crime. 
O Grotesco pelo seu potencial poético, foi além da ornamentação de objetos, ornamentou a literatura e a poesia, o cinema e o teatro; tornou-se categoria estética e literária, manifestando o desvio de uma norma expressiva dominante. Chegou incólume ao século XX, onde foi crucial para os movimentos da vanguarda histórica, como o Surrealismo e o Dadá e, se estendeu ao pós-moderno, nas obras de Cindy Sherman, por exemplo.

A crítica Rosalind Krauss classificou a obra de Sherman como "cópias sem originais" ${ }^{20}$. O grotesco é um recurso estético para denunciar convençôes. Em suas fotografias, a feminilidade é pensada fora da dicotomia feminino-masculino, e se revela no "entre". Um feminino "estranho" ou grotesco que escapa das fronteiras estabelecidas para, através da ironia, suscitar novas formas de reflexão, de questionamentos sobre modelos, valores e conceitos. O grotesco é algo que ameaça continuamente qualquer representação ou comportamento marcado pela excessiva idealização. Pela estranheza, pode-se fazer cair por terra tudo aquilo que a ideia eleva alto demais ${ }^{21}$. Tanto o arabesco quanto o grotesco não possuem (e nunca possuíram) um conceito fechado, mas ambos sempre foram empregados para "não representar" o real, o ordinário ou o básico, mas a ambivalência.

Curiosamente - ou seria isto uma primorosa ironia? - Peter Eisenman recorre a dois elementos puramente ornamentais, característicos da arte decorativa, ferozmente rechaçada pela arquitetura moderna, para transfigurá-los em conceitos que serão determinantes para o seu (re)pensar os limites da arquitetura. Mas, surpreendentemente, faz isso extraindo um potencial, de tal modo extraordinário, que permite o arabesco e o grotesco tornarem-se "texto", rompimento de oposiçóes e hieraquia de valores, esvaziamento de signos, turvarmento de fronteiras e sistemas de classificação convencional e, sobretudo, exploração poética. Em suma, uma copiosidade de recursos que fundamentam o próprio deslocamento da metafísica arquitetônica. Um deslocamento elementar na elaboração de uma arquitetura "entre".

O conceito de arabesco aparece na obra de Eisenman exclusivamente no ensaio Blue line text. $\mathrm{O}$ conceito de grotesco aparece no meSmo texto, e volta a ser mencionado em En Terror Firma: na trilha dos grotextos. Ambos os textos são de 1988. Não se encontram mais referências a esses termos em textos posteriores. Pode-se dizer, contudo, que a combinação de ambos norteia todo o trabalho do arquiteto, estabelecendo um repertório de mecanismos gráfico-formais fundamental para todo o seu trabalho. A ausência de menção ao arabesco e ao grotesco em seus escritos posteriores a 1988 não é, contudo, uma inconsistência: toda vez que Eisenman turva as hierarquias de valores e os sistemas classificatórios tradicionais ou contesta a representação como uma verdade inquestionável, o que está em operação é todo um sistema de conceitos que o arabesco e o grotesco representam.

A formulação desses conceitos (crucial na elaboração de uma arquitetura entre) foi um momento privilegiado de impulso poético, que serve de chave de leitura para todo o seu trabalho. No momento em que a linguagem poética torna-se um fator relevante para o seu pensamento, é aí que Eisenman produz as melhores condiçóes para investigar o ser da arquitetura e consequentemente, promover uma revisão da metafísica clássica. É quando ele elabora uma outra arquitetura: do arabesco e do grotesco. 
Eisenman leva a termo uma exploração crítica, investigando as condiçôes de possibilidade de uma autonomia da arquitetura. Para tanto, elabora uma "ficção", uma arquitetura inventada, como um escritor inventa um planeta fictício, com suas arquiteturas, mitologias, linguagem, seus mares, sua geografia, sua flora, fauna, sua álgebra, topografia e sua metafísica. Assim como os metafísicos de Tlön, que não procuram a verdade, nem sequer a verossimilhança, senão o assombro, Eisenman procura o sublime contemporâneo na sua figura do grotesco; persevera na constituição dessa ficção, não como um efeito do fingimento, mas como uma criação da imaginação, delineando rastros, traços, enxertos, índices, poéticas textuais, colapso de signos, incertezas no lugar de hierarquias, do arabesco ao grotesco: um repertório mecânico formal que permitiu Eisenman empreender uma crítica profunda da representação, assim como o desenvolvimento experimental da sintaxe da forma para examinar a conexáo entre os elementos da linguagem e a representação do pensamento.

Em sua Autobiografia Cientifica, Aldo Rossi questionou como o significado de real em arquitetura poderia ser interrogado. Ele evocou a lembrança de um verão de 1977 - uma conversa numa taberna sobre uma possível definição de arquitetura. "Havia um precipício de dez metros no ponto mais alto do quarto", Rossi recordou, questionando-se: "É possível viver em quartos com um precipício? É possível que um projeto deste tipo seja representável para além da memória e da experiência?"22. Sim! Em uma casa de Peter Eisenman, certamente.

Rossi diz ter tentado, em vão, desenhar este quarto, pois sempre se detinha em um vazio que não podia representar. Eisenman, por sua vez, empenhou-se em representar o vazio com a presença e a presença com a ausência, logrando uma representação formal do indeterminado, do atroz e do indizível.

Do arabesco ao grotesco.

\section{Notas de fim:}

1. EISENMAN, P. Blue Line. In: Select Writings, 19631998. Yale University Press: New Haven/London, 2004, p.237.

2. Idem, p.237.

3. I. Ibid, p.237.

4. Até o século XVIII, o sublime era definido por oposição dialética ao belo, mas Kant introduziu um novo conceito: algo que estaria no interior da beleza, que estava contido no belo assim como o belo estava contido no sublime. Outro modo de conceituar a beleza que não por referência ao bom ou natural.

5. EISENMAN, P. En Terror Firma: na trilha dos grotextos. In: NESBIT, K. Uma nova agenda para a arquitetura: antologia retórica: 1965-1995. 2a. Edição. São Paulo: Cosac \& Naify, 2006, p.614.

6. Na fase final de sua obra, Heidegger vê na poesia a linguagem que mais se aproxima desse encontro com o ser proposto em sua filosofia. MARCONDES, D. Textos Básicos de Filosofia: dos pré-socráticos a Wittgenstein. Rio de Janeiro: Zahar, 1999, p.147.

7. BORGES, Jorge Luis. Fiç̧ôes. Tradução: Carlos Nejar. 3a. Edição. São Paulo, Globo, 2001, p. 44.

8. ALLEN, S. et al. Tracing Eisenman: Peter Eisenman Complete Works. New York: Rizzoli, 2006, p.66.

9. VIDLER, A. Uma teoria sobre o estranhamente familiar. In: NESBIT, K. Uma nova agenda para a arquitetura: antologia retórica: 1965-1995. 2a. Edição. São Paulo: Co- 
sac \& Naify, 2006, p.621.

10. ALLEN, S. et al. Tracing Eisenman: Peter Eisenman Complete Works. New York: Rizzoli, 2006, p.76.

11. EISENMAN, P. Written Into the Void. In: Written into the Void: select writings 1990-2004, New Haven/ London: Yale University Press, 2007, p.77.

12. EISENMAN, P. Representation of Doubt: at the sign of the sign. In: Select Writings, 1963-1998. Yale University Press: New Haven/London, 2004, p. 148.

13. EISENMAN, P. Three Texts for Venice. In: The City of Artificial Excavation. Architectural Design, 53, 1983 , p. 27.

14. Eisenman elaborou um projeto em parceria com Derrida para o Parque de La Villette, denominado: Choral. 1982.

15. EISENMAN, P. Separate Tricks. In: Written into the Void. In: select writings 1990-2004, New Haven/ London: Yale University Press, 2007, p.77.

16. Idem, p. 74-78.

17. Id. Ibid. p. 74-78.

18. ZULIANI, G. et al. Tracing Eisenman: Peter Eisenman Complete Works. New York: Rizzoli, 2006, p.392.

19. Idem.

20. THORTON, S. O que é um artista? Nos bastidores da arte contemporânea. Tradução: Alexandre Barbosa. Rio de Janeiro: Zahar, 2015, p.189.

21. CABRAL, A.; SOARES, R. O Império do Grotesco. Mauad, 2002, p.39.

22. ROSSI, A. Autobiografia Científica. Edições 70, Lisboa, 2013, p.51.

\section{Referências Bibliográficas}

ALLEN, S. et al. Tracing Eisenman: Peter Eisenman Complete Works. New York: Rizzoli, 2006.

BORGES, J. L. Ficçôes. Tradução: Carlos Nejar. São Paulo: Globo, 2001.

CABRAL, Muniz Sodré A.; SOARES, Raquel Paiva de A. O Império do Grotesco. Mauad, 2002.

EISENMAN, P. Blue Line. In: Select Writings, 1963-1998. Yale University Press: New Haven/ London, p 234-237. 2004.

A arquitetura e o problema da figura retórica. In: NESBIT, K. Uma nova agenda para a arquitetura: antologia retórica: 1965-1995. São Paulo: Cosac \& Naify, p.191-199, 2006.

Written into the Void. In: Written Into the Void: select writings 1990-2004, New Haven/ London: Yale University Press, p. 79-86, 2007.

En Terror Firma: na trilha dos grotextos. In: NESBIT, K. Uma nova agenda para a arquitetura: antologia retórica: 1965-1995. São Paulo: Cosac \& Naify, p.611-617, 2006.

Representation of Doubt: at the sign of the sign. In: Select Writings, 1963-1998. Yale University Press: New Haven/London, 2004.

Separate Tricks. In: Written into the Void. In: Select Writings 1990-2004, New Haven/ London: Yale University Press, 2007.

MARCONDES, D. Textos Básicos de Filofosia: dos pré-socráticos a Wittgenstein. Rio de Janeiro: Zahar, 1999.

ROSSI, A. Autobiografia Cientifica. Ediçōes 70, Lisboa, 2013. 